\title{
Nitric oxide increases cyclic GMP levels, AMP-activated protein kinase (AMPK) $\alpha 1$-specific activity and glucose transport in human skeletal muscle
}

\author{
A. S. Deshmukh • Y. C. Long • T. de Castro Barbosa • H. K. R. Karlsson • S. Glund • \\ W. J. Zavadoski • E. M. Gibbs • H. A. Koistinen • H. Wallberg-Henriksson • \\ J. R. Zierath
}

Received: 9 February 2010 / Accepted: 11 February 2010/Published online: 27 March 2010

(C) The Author(s) 2010. This article is published with open access at Springerlink.com

\begin{abstract}
Aims/hypothesis We investigated the direct effect of a nitric oxide donor (spermine NONOate) on glucose transport in isolated human skeletal muscle and L6 skeletal muscle cells. We hypothesised that pharmacological treatment of human skeletal muscle with N-(2-aminoethyl)-N-(2-hydroxy-2-nitrosohydrazino)-1,2-ethylenediamine (spermine NONOate)
\end{abstract}

A. S. Deshmukh • Y. C. Long • T. de Castro Barbosa •

H. K. R. Karlsson · S. Glund · H. Wallberg-Henriksson •

J. R. Zierath $(\bowtie)$

Department of Molecular Medicine and Surgery,

Section of Integrative Physiology, Karolinska Institutet,

von Eulers väg 4, 4th floor,

S-171 77 Stockholm, Sweden

e-mail: Juleen.Zierath@ki.se

W. J. Zavadoski • E. M. Gibbs

Department of Cardiovascular, Metabolic and Endocrine Diseases,

Pfizer Global Research and Development,

Groton, CT, USA

H. A. Koistinen

Department of Medicine, Division of Cardiology,

Helsinki University Central Hospital,

Helsinki, Finland

H. A. Koistinen

Minerva Foundation Institute for Medical Research,

Biomedecum 2U,

Helsinki, Finland

H. Wallberg-Henriksson · J. R. Zierath

Department of Physiology and Pharmacology,

Section of Integrative Physiology, Karolinska Institutet,

Stockholm, Sweden

Present Address:

E. M. Gibbs

Gibbs Biomedical Consultants, LLC,

Oakdale, CT, USA would increase intracellular cyclic GMP (cGMP) levels and promote glucose transport.

Methods Skeletal muscle strips were prepared from vastus lateralis muscle biopsies obtained from seven healthy men. Muscle strips were incubated in the absence or presence of $5 \mathrm{mmol} / 1 \mathrm{spermine}$ NONOate or $120 \mathrm{nmol} / \mathrm{l}$ insulin. The $\mathrm{L} 6$ muscle cells were treated with spermine NONOate $(20 \mu \mathrm{mol} / \mathrm{l})$ and incubated in the absence or presence of insulin $(120 \mathrm{nmol} / \mathrm{l})$. The direct effect of spermine NONOate and insulin on glucose transport, cGMP levels and signal transduction was determined.

Results In human skeletal muscle, spermine NONOate increased glucose transport 2.4-fold $(p<0.05)$, concomitant with increased cGMP levels ( 80 -fold, $p<0.001$ ). Phosphorylation of components of the canonical insulin signalling cascade was unaltered by spermine NONOate exposure, implicating an insulin-independent signalling mechanism. Consistent with this, spermine NONOate increased AMPactivated protein kinase (AMPK)- $\alpha 1$-associated activity (1.7-fold, $p<0.05)$. In L6 muscle cells, spermine NONOate increased glucose uptake $(p<0.01)$ and glycogen synthesis $(p<0.001)$, an effect that was in addition to that of insulin. Spermine NONOate also elicited a concomitant increase in AMPK and acetyl-CoA carboxylase phosphorylation. In the presence of the guanylate cyclase inhibitor LY-83583 $(10 \mu \mathrm{mol} / 1)$, spermine NONOate had no effect on glycogen synthesis and AMPK- $\alpha 1$ phosphorylation.

Conclusions/interpretation Pharmacological treatment of skeletal muscle with spermine NONOate increases glucose transport via insulin-independent signalling pathways involving increased intracellular cGMP levels and AMPK- $\alpha 1$ associated activity.

Keywords Contraction · Exercise - GLUT4 .

Spermine NONOate 


\begin{tabular}{|c|c|}
\hline Abbreviations & \\
\hline $\mathrm{ACC}$ & Acetyl-CoA carboxylase \\
\hline AICAR & $\begin{array}{l}5^{\prime} \text {-Aminoimidazole-4-carboxamide } \\
\text { ribonucleoside }\end{array}$ \\
\hline AMPK & AMP-activated protein kinase \\
\hline CaMK & $\begin{array}{l}\mathrm{Ca}^{2+} \text {-calmodulin-dependent protein } \\
\text { kinase }\end{array}$ \\
\hline cGMP & Cyclic GMP \\
\hline GSK & Glycogen synthase kinase \\
\hline KHB & Krebs-Henseleit buffer \\
\hline NOS & Nitric oxide synthase \\
\hline PAS & Phospho-Akt substrate \\
\hline Rab & $\begin{array}{l}\text { Rev/Rex activation domain- } \\
\text { binding protein }\end{array}$ \\
\hline Spermine NONOate & $\begin{array}{l}N \text {-(2-Aminoethyl)- } N \text {-(2-hydroxy- } \\
\text { 2-nitrosohydrazino)-1,2- } \\
\text { ethylenediamine }\end{array}$ \\
\hline $\mathrm{TBC} 1$ & $\begin{array}{l}\text { Tre-2/BUB2/CDC16 domain- } \\
\text { containing protein family, member } 1\end{array}$ \\
\hline
\end{tabular}

\section{Introduction}

Nitric oxide is implicated in a wide array of signalling networks [1]. In rodents and humans, exercise increases skeletal muscle nitric oxide production, concomitant with increased glucose uptake [2-4]. Nitric oxide biogenesis is catalysed by different isoforms of nitric oxide synthase (NOS) [5], of which neuronal-type NOS and endothelialtype NOS isoforms are produced in skeletal muscle [1]. Neuronal-type NOS is produced at higher levels in human skeletal muscle than brain [6] and therefore is likely to be the major isoform involved in the effect of nitric oxide on glucose metabolism [1]. Acute administration of the NOS inhibitor NG-monomethyl-L-arginine during exercise in humans reduces leg muscle glucose uptake [4], implicating nitric oxide signalling in the mechanism by which exercise controls glucose homeostasis.

The intracellular mechanism by which nitric oxide increases skeletal muscle glucose uptake in humans is incompletely resolved. Intra-femoral artery infusion of a nitric oxide donor increased glucose uptake in healthy participants [7], as well as in type 2 diabetic patients [8]. Furthermore, exposure of isolated rat skeletal muscle to the nitric oxide donor sodium nitroprusside increased glucose transport in a dose-dependent manner [9, 10]. Stimulation of glucose transport by nitric oxide involves the activation of a calcium/contraction- and phosphatidylinositol-3kinase-independent pathway that acutely increases GLUT4 content at the cell surface [11]. Nitric oxide seems to exert its action on muscle glucose transport partly via activation of guanylate cyclase, leading to elevation of cyclic GMP
(cGMP) levels $[10,12]$. Indeed, the cGMP analogue 8bromo-cGMP also increases glucose uptake in isolated rat skeletal muscle [10]. Thus, nitric oxide/cGMP signalling may be part of a novel pathway that regulates skeletal muscle glucose uptake.

The effect of exercise on the acute regulation of skeletal muscle glucose transport has been attributed to several signalling nodes including $\mathrm{Ca}^{2+}$-calmodulin-dependent protein kinase (CaMK)II, AMP-activated protein kinase (AMPK) and nitric oxide [13]. In this regard, the interaction between AMPK and nitric oxide signalling pathways is especially intriguing. AMPK is a serine/threonine protein kinase, which acts as a sensor of cellular energy status and regulates a wide variety of gene regulatory and metabolic pathways, including glucose uptake and fatty acid oxidation in skeletal muscle [14]. AMPK subunits $(\alpha 1, \alpha 2, \beta 1, \beta 2$, $\gamma 1, \gamma 2, \gamma 3)$ form a heterotrimeric enzyme consisting of $\alpha$ (catalytic), and $\beta$ and $\gamma$ (regulatory) isoforms. In rodent skeletal muscle, sodium nitroprusside increases glucose transport, concomitant with $\alpha 1$-associated AMPK activation [15]. Moreover, chronic exposure of L6 muscle cells to sodium nitroprusside increases Glut4 (also known as SLC2A4) mRNA expression by an AMPK-dependent mechanism [16], positioning AMPK downstream of nitric oxide signalling. AMPK is also considered to be an upstream kinase for NOS, since it phosphorylates and activates endothelial and neuronal NOS [17-19]. Thus, a positive feedback interaction between AMPK and NOS in the control of skeletal muscle metabolism is implicated [16].

In the present study, we determined the effect of the nitric oxide donor spermine $\mathrm{N}$-(2-aminoethyl)- $\mathrm{N}$-(2-hydroxy-2-nitrosohydrazino)-1,2-ethylenediamine NONOate on glucose transport and intracellular signalling in isolated human skeletal muscle. Using L6 skeletal muscle cells, we also determined whether spermine NONOate and insulin have additive effects on glucose uptake and intracellular signalling. We hypothesised that pharmacological treatment of human skeletal muscle with a compound that increases cGMP levels may promote glucose uptake.

\section{Methods}

Study participants The study protocol was approved by the regional Ethics Committee at Karolinska Institutet. Informed consent was received from all participants $(n=7)$ before participation. The clinical characteristics of the healthy male volunteers are presented in Table 1. Glucose, insulin and $\mathrm{HbA}_{1 \mathrm{c}}$ values were within the normal range, with no elevation of serum aminotransferase levels. None of the participants used tobacco products or reported taking any medication. The participants were asked to refrain from 
Table 1 Clinical characteristics of the study participants

\begin{tabular}{lc}
\hline Characteristics & Mean \pm SE \\
\hline Age (year) & $50.1 \pm 3.8$ \\
Weight $(\mathrm{kg})$ & $78.6 \pm 2.5$ \\
Height $(\mathrm{cm})$ & $178.6 \pm 2.4$ \\
BMI $\left(\mathrm{kg} / \mathrm{m}^{2}\right)$ & $24.8 \pm 0.88$ \\
Insulin $(\mathrm{pmol} / \mathrm{l})$ & $30 \pm 7.3$ \\
Plasma glucose (mmol/l) & $5.2 \pm 0.2$ \\
HbA $(\%)$ & $4.4 \pm 0.1$ \\
Total cholesterol (mmol/l) & $4.9 \pm 0.24$ \\
HDL $(\mathrm{mmol} / \mathrm{l})$ & $1.5 \pm 0.1$ \\
LDL $(\mathrm{mmol} / \mathrm{l})$ & $3.4 \pm 0.2$ \\
Triacylglycerol $(\mathrm{mmol} / \mathrm{l})$ & $1.0 \pm 0.3$ \\
ASAT $(\mu \mathrm{kat} / \mathrm{l})$ & $0.40 \pm 0.04$ \\
ALAT $(\mu \mathrm{kat} / \mathrm{l})$ & $0.41 \pm 0.05$ \\
$\gamma$-GT $(\mu \mathrm{kat} / \mathrm{l})$ & $0.48 \pm 0.19$ \\
\hline
\end{tabular}

Results are presented as mean \pm SEM for $n=7$ participants

ALAT, alanine aminotransferase; ASAT, aspartate aminotransferase; $\gamma$-GT, gamma-glutamyltransferase

strenuous exercise for $48 \mathrm{~h}$ before the study and to report to the laboratory after an overnight fast.

Muscle biopsy procedure Skeletal muscle $(\sim 1 \mathrm{~g})$ was obtained by means of an open biopsy. Biopsies were taken under local anaesthesia (mepivakain chloride $5 \mathrm{mg} / \mathrm{ml}$ ) from the vastus lateralis portion of the quadriceps femoris muscle [20]. An incision $(\sim 4 \mathrm{~cm})$ was made $15 \mathrm{~cm}$ above the proximal border of patella and the muscle fascia was exposed. Thereafter, four to five muscle fibre bundles were excised and placed in oxygenated Krebs-Henseleit buffer (KHB), which contained $5 \mathrm{mmol} / 1$ glucose, $15 \mathrm{mmol} /$ 1 mannitol and 0.1\% (wt/vol.) BSA (RIA Grade; Sigma, St Louis, MO, USA).

Muscle incubation procedure Smaller skeletal muscle strips were dissected from the biopsy specimen, mounted on Plexiglass clamps ( $9 \mathrm{~mm}$ in width) and incubated in vitro in pregassed $\left(95 \% \mathrm{O}_{2}\right.$ and $\left.5 \% \mathrm{CO}_{2}\right) \mathrm{KHB}$ in a shaking water bath at $35^{\circ} \mathrm{C}$ for $30 \mathrm{~min}$. The gas phase in the vials was maintained during the incubation procedure. Thereafter, skeletal muscle strips were incubated for $30 \mathrm{~min}$ at $35^{\circ} \mathrm{C}$ in KHB in the absence (basal) or presence of either $5 \mathrm{mmol} / \mathrm{l}$ spermine NONOate (Calbiochem, San Diego, CA, USA) or $120 \mathrm{nmol} / 1$ insulin (Insulin Actrapid; Novo Nordisk, Bagsværd, Denmark). The concentrations of spermine NONOate and insulin were maintained throughout all remaining incubation procedures.

Glucose transport Skeletal muscle strips were transferred to fresh KHB containing $20 \mathrm{mmol} / \mathrm{l}$ mannitol and incubated at $35^{\circ} \mathrm{C}$ for $10 \mathrm{~min}$. Thereafter, muscles were incubated for $20 \mathrm{~min}$ in KHB containing $5 \mathrm{mmol} / \mathrm{l}$ 3-O-methyl $\left[{ }^{3} \mathrm{H}\right]$ glucose $(29.6 \mathrm{MBq} / \mathrm{mmol})$ and $15 \mathrm{mmol} / 1\left[{ }^{14} \mathrm{C}\right]$ mannitol (2.0 MBq/mmol). Thus, muscle strips were exposed to either spermine NONOate or insulin for a total of $60 \mathrm{~min}$. At the end of the incubation protocol, skeletal muscle specimens were blotted of excess fluid, snap-frozen in liquid nitrogen and stored at $-80^{\circ} \mathrm{C}$ until further analysis. Glucose transport was determined by the accumulation of intracellular 3-O-methyl- $\left[{ }^{3} \mathrm{H}\right]$ glucose as previously described [21].

Cyclic guanosine monophosphate measurement Skeletal muscle strips were incubated in the absence or presence of spermine NONOate as described above for $60 \mathrm{~min}$ and then rapidly clamp frozen in liquid $\mathrm{N}_{2}$ cooled tongs. Frozen muscles were homogenised on ice in $1 \mathrm{ml} 10 \%$ (vol./vol.) trichloroacetic acid using a polytron. Homogenates were subjected to centrifugation for $10 \mathrm{~min}$ at $14,000 \mathrm{~g}$. Thereafter, the trichloroacetic acid was extracted from the supernatant fraction with ${ }^{2} \mathrm{H}_{2} \mathrm{O}$-saturated diethyl ether. Samples were then immediately frozen in liquid $\mathrm{N}_{2}$ and concentrated in a speed vacuum. The concentrated samples were resuspended in assay buffer and acetylated, after which cGMP levels were measured by immunoassay according to manufacturer's instructions (cGMP BioTRAK, RPN 226; Amersham, Pittsburgh, PA, USA). cGMP is expressed as $\mathrm{pmol} / \mathrm{g}$ wet weight.

AMP kinase activity Muscles were homogenised in ice-cold lysis buffer containing $50 \mathrm{mmol} / \mathrm{l}$ Tris $-\mathrm{HCl}(\mathrm{pH} \mathrm{7.5)}$, $1 \mathrm{mmol} / \mathrm{l}$ EDTA, $1 \mathrm{mmol} / \mathrm{l}$ dithiothreitol, $10 \%$ (vol./vol.) glycerol, $50 \mathrm{mmol} / \mathrm{l} \mathrm{NaF}, 5 \mathrm{mmol} / \mathrm{l} \mathrm{Na}$ pyrophosphate, $1 \mathrm{mmol} / 1$ benzamidine, $0.1 \mathrm{mmol} / 1$ phenylmethyl sulfonyl fluoride and 1\% (vol./vol.) Triton X-100. Muscle homogenates were subjected to centrifugation for $10 \mathrm{~min}$ at $14,000 \mathrm{~g}$ and $4^{\circ} \mathrm{C}$. Supernatant fractions were removed and used to determine protein content using a commercially available kit based on the Bradford method (Bio-Rad, Hercules, CA, USA). Aliquots (200 $\mu \mathrm{g}$ protein) were incubated overnight at $4{ }^{\circ} \mathrm{C}$ with antibodies against $\alpha 1$ and $\alpha 2$-AMPK subunits (provided by D. G. Hardie, Division of Molecular Physiology, College of Life Sciences, University of Dundee, Dundee, UK). Human muscle lysates from rested and exercised conditions were also incubated overnight at $4{ }^{\circ} \mathrm{C}$ with antibodies against the AMPK- $\alpha 1$ - and $\alpha 2$-subunits, and were used as positive control for the assay. The immunoprecipitates were washed once in lysis buffer, once in $480 \mathrm{mmol} / 1$ HEPES (pH 7.0) and $240 \mathrm{mmol} / \mathrm{l} \mathrm{NaCl}$, and twice in $240 \mathrm{mmol} /$ 1 HEPES (pH 7.0) and $120 \mathrm{mmol} / \mathrm{l} \mathrm{NaCl}$, leaving $10 \mu \mathrm{l}$ of buffer with the Sepharose after the last wash. To determine isoform-specific AMPK activity, the immunoprecipitates 
were incubated for $30 \mathrm{~min}$ at $30^{\circ} \mathrm{C}$ in a total volume of $30 \mu \mathrm{l}$ containing $833 \mu \mathrm{mol} / 1$ diothiothreitol, $200 \mu \mathrm{mol} / 1 \mathrm{AMP}$, $100 \mu \mathrm{mol} / 1$ AMARA-peptide (Upstate Millipore, Billerica, MA, USA), $5 \mathrm{mmol} / 1 \mathrm{MgCl}_{2}, 200 \mu \mathrm{mol} / 1 \mathrm{ATP}$ and $74 \mathrm{kBq}$ of $\left[\gamma_{-}{ }^{32} \mathrm{P}\right] \mathrm{ATP}$. The reaction was stopped by spotting $25 \mu 1$ on to a piece of P81 filter paper, which was then washed four times at $15 \mathrm{~min}$ per time in $1 \%$ (vol./vol.) phosphoric acid. The dried filter paper was analysed for activity using liquid scintillation counting.

Cell culture L6 muscle cells (provided by A. Klip, The Hospital for Sick Children, Toronto, ON, Canada) were grown in $\alpha$ MEM supplemented with $10 \%$ (vol./vol.) FBS, $1 \%$ (vol./vol.) penicillin and streptomycin $(100 \mathrm{U} / \mathrm{ml}$ penicillin, $100 \mu \mathrm{g} / \mathrm{ml}$ streptomycin), and $1 \%$ (vol./vol.) fungizone in $5 \% \mathrm{CO}_{2} 95 \% \mathrm{O}_{2}$ humidified air at $37^{\circ} \mathrm{C}$. The L6 cells were differentiated into myotubes for 6 days in $\alpha$ MEM supplemented with $2 \%$ (vol./vol.) FBS. Myotubes were then serum-starved for $3 \mathrm{~h}$ before the start of the experiment. Myotubes were incubated under basal conditions or in the presence or absence of spermine NONOate $(20 \mu \mathrm{mol} / \mathrm{l})$ or a guanylate cyclase inhibitor $(10 \mu \mathrm{mol} / \mathrm{l} \mathrm{LY}$ 83583) and glucose incorporation into glycogen (glycogen synthesis), glucose uptake and protein signalling were determined. To establish insulin-stimulated conditions, insulin $(120 \mathrm{nmol} / \mathrm{l})$ was added during the last $20 \mathrm{~min}$ for protein phosphorylation and glucose uptake analysis or during the last $120 \mathrm{~min}$ for glycogen synthesis analysis.

Glucose incorporation to glycogen (glycogen synthesis) Glycogen synthesis was assessed in L6 cells by measuring the incorporation of $\mathrm{D}-\left[\mathrm{U}-{ }^{14} \mathrm{C}\right]$ glucose into glycogen as described [22]. Overnight serum-starved myotubes were incubated in 6 well plates and treated for $1 \mathrm{~h}$ with spermine NONOate $(20 \mu \mathrm{mol} / \mathrm{l})$ and LY-83583 $(10 \mu \mathrm{mol} / \mathrm{l})$, in the absence or presence of insulin $(120 \mathrm{nmol} / \mathrm{l})$. During the last $90 \mathrm{~min}$, the cells were incubated with medium supplemented with glucose $(5 \mathrm{mmol} / \mathrm{l})$ and $\mathrm{D}-\left[\mathrm{U}-{ }^{14} \mathrm{C}\right]$ glucose (final specific activity, $37 \mathrm{kBq} / \mathrm{ml}$ ). Each experiment was performed on duplicate wells. Glucose uptake and incorporation to glycogen was determined as mmol glucose per mg protein per $h$.

Glucose uptake Myotubes were serum-starved for 3 to $5 \mathrm{~h}$ and incubated with or without spermine NONOate $(20 \mu \mathrm{mol} / \mathrm{l})$ in the absence or presence of insulin (120 nmol/l). 2-Deoxyglucose uptake was determined as described [23]. Each experiment was performed on duplicate wells.

Western blot analysis A portion of the muscle specimen incubated for the glucose transport assay was homogenised in $0.3 \mathrm{ml}$ ice-cold lysis buffer using a glass-on-glass system with a motor pestle. The buffer contained $20 \mathrm{mmol} / \mathrm{l}$ Tris $(\mathrm{pH} 8.0)$, $137 \mathrm{mmol} / 1 \mathrm{NaCl}, 2.7 \mathrm{mmol} / \mathrm{l} \mathrm{KCl}, 10 \mathrm{mmol} / \mathrm{l} \mathrm{NaF}, 1 \mathrm{mmol} / \mathrm{l}$ $\mathrm{MgCl}_{2}, 1 \mathrm{mmol} / 1 \mathrm{Na}_{3} \mathrm{VO}_{4}, 0.2 \mathrm{mmol} / \mathrm{l}$ phenylmethylsulfonyl fluoride, $10 \%$ (wt/vol.) glycerol, $1 \%$ (wt/vol.) Triton X-100, $1 \mu \mathrm{g} / \mathrm{ml}$ aprotinin, $1 \mu \mathrm{g} / \mathrm{ml}$ leupeptin and $1 \mu \mathrm{mol} / \mathrm{l}$ microcystin. L6 myotubes were collected into similar ice-cold lysis buffer. Homogenates were solubilised by end-over-end mixing for $60 \mathrm{~min}$ at $4^{\circ} \mathrm{C}$ and subjected to centrifugation (for $10 \mathrm{~min}$ at $4^{\circ} \mathrm{C}$ and $12,000 \mathrm{~g}$ ). The supernatant fraction was stored at $-80^{\circ} \mathrm{C}$ until use. Total protein was determined using a commercially available kit (Pierce, Rockford, IL, USA). Equal amounts of protein $(40 \mu \mathrm{g})$ were diluted in Laemmli sample buffer. Proteins were separated by SDS-PAGE and transferred to membranes (Immobilon-P; Millipore). Phosphorylation and levels of several proteins were determined using the following antibodies: phospho-AMPK $\mathrm{Thr}^{172}$, phospho-Akt $\mathrm{Ser}^{473}$, phospho-Akt-substrate (PAS), phospho-glycogen synthase kinase (GSK)- $\alpha / \beta\left(\mathrm{Ser}^{21 / 9}\right.$ ) and phospho-CaMKII $\mathrm{Thr}^{286}$ (all from Cell Signaling Technology, MA, USA), phospho-ACC $\beta$ $\mathrm{Ser}^{227}$ and ACC (Upstate Biotechnologies, MA, USA) and GLUT4 (Chemicon, CA, USA). Anti- $\alpha 1$-AMPK and anti $\alpha 2$ AMPK antibodies used for the immunoblot analysis were kindly provided by D. G. Hardie (Division of Molecular Physiology, College of Life Sciences, University of Dundee, UK). All membranes were normalised for loading with glyceraldehyde-3-phosphate dehydrogenase (Santa Cruz Biotechnology, Santa Cruz, CA, USA) or respective total protein content. Proteins were visualised by chemiluminescence and quantified by densitometry.

Statistics Data are reported as mean \pm SE. Differences were determined using a paired $t$ test or ANOVA as appropriate. Bonferroni test was used for post hoc analysis. Significance was established at $p<0.05$.

\section{Results}

Effects of spermine NONOate on glucose transport and AMP kinase activity We determined the effects of spermine NONOate and insulin on glucose transport in intact human skeletal muscle (Fig. 1a). Muscle strips were incubated in the absence or presence of either $5 \mathrm{mmol} / \mathrm{l}$ spermine NONOate or $120 \mathrm{nmol} / \mathrm{l}$ insulin and 3-O-methyl-glucose transport was assessed. Insulin increased glucose transport fivefold $(p<0.05)$ in isolated skeletal muscle strips, consistent with our earlier studies [24]. Spermine NONOate increased skeletal muscle glucose transport 2.4-fold ( $p<$ $0.05)$, concomitant with increased cGMP levels $(p<0.001)$ (Fig. 1b). AMPK activation has been implicated in the mechanism by which nitric oxide enhances glucose uptake in skeletal muscle [15]. Thus, we determined the effects of 

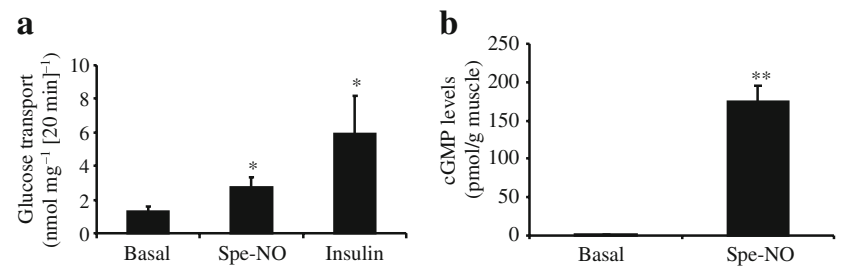

c
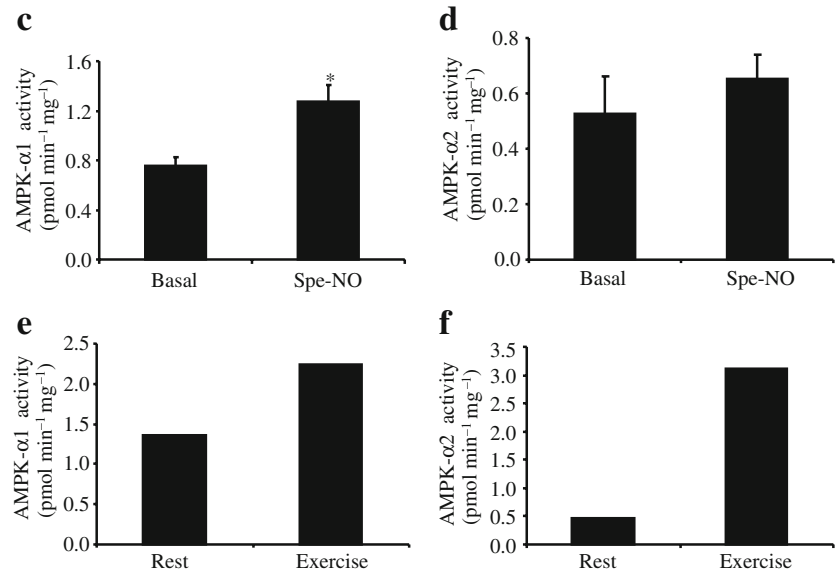

Fig. 1 Effect of spermine nitric oxide donor on glucose transport, cGMP content and AMPK activity in human skeletal muscle. Skeletal muscle strips from seven healthy men were incubated in the absence (basal) or presence of spermine NONOate (Spe-NO, nitric oxide donor; $5 \mathrm{mmol} / \mathrm{l})$ or insulin $(120 \mathrm{nmol} / \mathrm{l})$. Glucose transport (a), intracellular cyclic GMP (cGMP) content (b), and both AMPK- $\alpha 1$ (c) and AMPK- $\alpha 2$ (d) isoform-specific activity were determined. e AMPK- $\alpha 1$ and AMPK- $\alpha 2$ (f) isoform-specific activity in skeletal muscle from healthy men $(n=2)$ in response to acute exercise. Results are expressed as mean \pm SEM. $* p<0.05, * * p<0.01$ vs basal

spermine NONOate exposure on $\alpha$-isoform-specific AMPK signalling (Fig. 1c, d). For perspective, acute exercise increased AMPK- $\alpha 1$ - and AMPK- $\alpha 2$-associated activity in skeletal muscle from healthy men by two- and 6.2-fold, respectively vs rested conditions (Fig. 1e, f). Spermine NONOate increased AMPK- $\alpha 1$-associated activity 1.7-fold $(p<0.05)$, while AMPK- $\alpha 2$-associated activity was unchanged in isolated skeletal muscle. Previous studies from our laboratory provide evidence that insulin does not alter AMPK- $\alpha 1$ - or AMPK- $\alpha 2$-associated activity in isolated human skeletal muscle [25].

Effects of spermine NONOate on protein content and signal transduction The effects of insulin or spermine NONOate on canonical insulin signalling were determined in isolated skeletal muscle using phospho-specific antibodies (Fig. 2a). Exposure of human skeletal muscle to insulin increased the phosphorylation of Akt $\left(\mathrm{Ser}^{473}\right)$, Tre-2/BUB2/CDC16 domain-containing protein family, member 1 , domain family 1 /domain family 4 (pTBC1D1/D4) (detected using a PAS antibody) and GSK3 $\alpha / \beta\left(\operatorname{Ser}^{21 / 9}\right)$, while spermine NONOate had no effect (Fig. 2a-d). Neither insulin nor spermine NONOate treatment altered CaMK signalling, since phosphorylation of CaMKII $\left(\mathrm{Thr}^{286}\right)$ was unaltered compared with non-stimulated (basal) muscle (Fig. 2e). Abundance of the AMPK- $\alpha 1$ and AMPK- $\alpha 2$ subunits in isolated skeletal muscle was unaltered after $1 \mathrm{~h}$ exposure of isolated skeletal muscle to spermine NONOate or insulin (Fig. 2a). In L6 cells, nitric oxide is known to increase GLUT4 levels via an AMPK-dependent mechanism [16]. GLUT4 content was unaltered after $1 \mathrm{~h}$ exposure of isolated skeletal muscle to spermine NONOate or insulin (data not shown), suggesting spermine NONOate acutely increases glucose transport in muscle by recruiting existing glucose transporters to the cell surface, rather than through GLUT4 biogenesis.

Effect of spermine NONOate and insulin on glycogen synthesis and glucose uptake To determine whether spermine NONOate and insulin have an additive effect on glucose metabolism, we measured glucose incorporation into glycogen (glycogen synthesis) (Fig. 3a) and glucose uptake (Fig. 3b) in L6 myotubes. Spermine NONOate and insulin increased glycogen synthesis 1.2- $(p<0.001)$ and 2.2 -fold $(p<0.0001)$, respectively (Fig. 3a). Combined
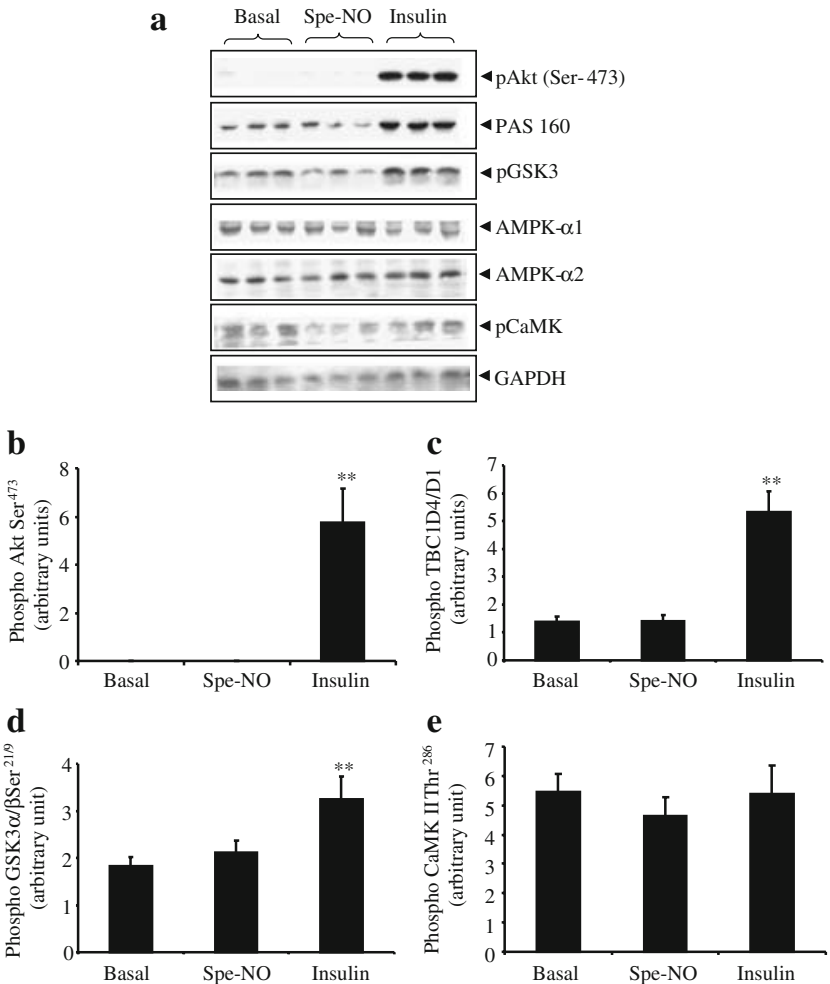

Fig. 2 Effect of spermine nitric oxide donor on intracellular signalling. Skeletal muscle strips from seven healthy participants were incubated in the absence (basal) or presence of spermine NONOate (Spe-NO, nitric oxide donor; $5 \mathrm{mmol} / \mathrm{l})$ or insulin $(120 \mathrm{nmol} / \mathrm{l})$. a Representative immunoblots of protein phosphorylation and abundance. GAPDH, glyceraldehyde-3-phosphate dehydrogenase. Bar graphs show quantification for (b) pAkt $\left(\operatorname{Ser}^{473}\right)$, (c) pTBC1D1/D4, (d) $\mathrm{pGSK} 3 \alpha / \beta\left(\mathrm{Ser}^{21 / 9}\right)$ and (e) pCaMK II $\left(\mathrm{Thr}^{286}\right)$. Results $(\mathbf{b}-\mathbf{e})$ are mean \pm SEM arbitrary units. ${ }^{* *} p<0.01$ vs basal 

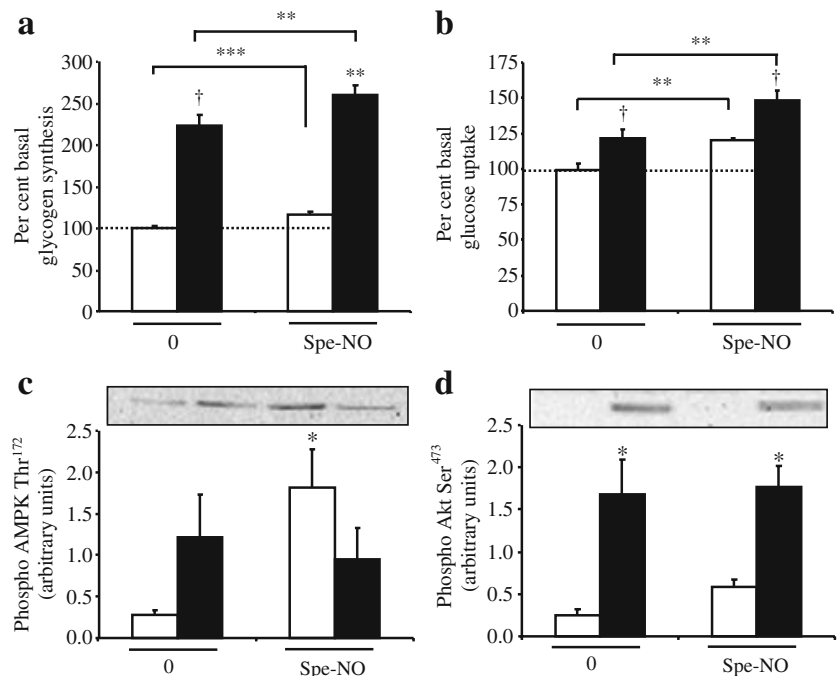

e
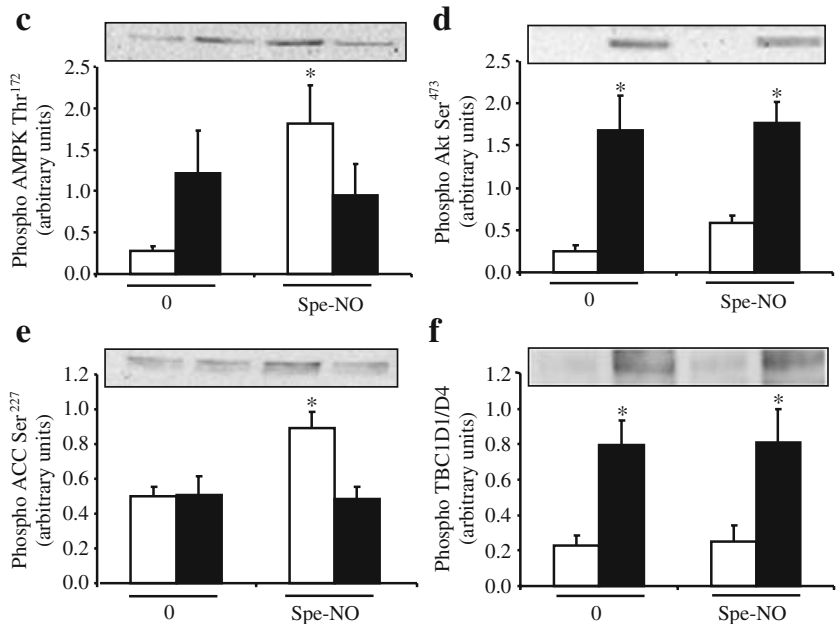

f

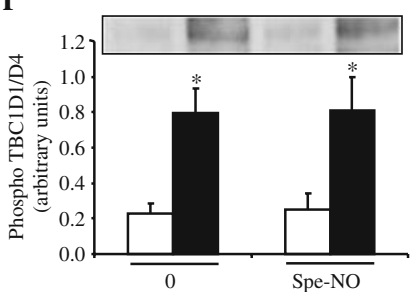

Fig. 3 Effect of spermine NONOate and insulin on glucose metabolism and intracellular signalling in L6 myotubes. Myotubes were treated with spermine NONOate (Spe-NO, nitric oxide donor; $20 \mu \mathrm{mol} / \mathrm{l}$ ), in the absence (white bars) or presence (black bars) of insulin. a Glucose incorporation into glycogen $(n=13-15)$ and (b) glucose uptake $(n=10-15)$ were determined. Results are expressed as mean \pm SEM percentage of basal values. Signal transduction was also determined for (c) pAMPK $\left(\mathrm{Thr}^{172}\right)$, (d) pAkt $\left(\mathrm{Ser}^{473}\right),(\mathbf{e})$ pACC $\left(\mathrm{Ser}^{227}\right)$ and $(\mathbf{f}) \mathrm{pTBC1D} 1 / \mathrm{D} 4(n=5-7)$. Results are mean $\pm \mathrm{SEM}$ arbitrary units. ${ }^{*} p<0.05,{ }^{*} p<0.01$ (two-way ANOVA, followed by Bonferroni post-test); $* * * p<0.001$ (one-way ANOVA, followed by Bonferroni post hoc test); ${ }^{\dagger} p<0.0001$ vs basal

exposure to spermine NONOate and insulin had an additive effect on glycogen synthesis. Similarly, spermine NONOate and insulin independently increased glucose uptake 1.2$(p<0.01)$ and 1.2-fold $(p<0.001)$ (Fig. 3b). Combined exposure to spermine NONOate and insulin also had an additive effect on glucose uptake. To delineate underlying mechanism for the additive effect on glucose uptake and metabolism, phosphorylation of AMPK, ACC, Akt and TBC1D1/D4 was measured (Fig. 3c-f). Spermine NONOate alone increased phosphorylation of AMPK $\mathrm{Thr}^{172}$ 6.3fold $(p<0.05)$ and $\mathrm{pACC} \mathrm{Ser}{ }^{227} 1.7$-fold $(p<0.05)$, while insulin alone had no effect. Interestingly, phosphorylation of AMPK Thr ${ }^{172}$ and pACC $\mathrm{Ser}^{227}$ was unaltered in the presence of spermine NONOate and insulin. Nevertheless, insulin led to a 6.5-fold increase in Akt $\mathrm{Ser}^{473}$ phosphorylation $(p<0.05)$ and a 3.5 -fold increase in TBC1D1/D4 phosphorylation $(p<0.05)$, these responses being unaltered in presence of spermine NONOate. Finally, phosphoryla- tion of Akt $\mathrm{Ser}^{473}$ and TBC1D1/D4 was unaltered in the presence of spermine NONOate.

Effect of the guanylate cyclase inhibitor LY-83583 on spermine NONOate-induced glycogen synthesis and AMPK phosphorylation An earlier report provides evidence that LY-83583 inhibits guanylate cyclase activity [26]. Since spermine NONOate exposure increased AMPK- $\alpha 1$ associated activity in human skeletal muscle (Fig. 1c), as well as phosphorylation of AMPK and ACC in L6 myotubes (Fig. 3c, e), we determined whether AMPK activation lies downstream of cGMP. Treatment of L6 myotubes with spermine NONOate increased glycogen synthesis and AMPK $\mathrm{Thr}^{172}$ phosphorylation, but these responses were abolished in the presence of LY- 83583 $(10 \mu \mathrm{mol} / \mathrm{l})$ (Fig. 4a, b). However, LY-83583 (10 $\mu \mathrm{mol} / \mathrm{l})$ increased glycogen synthesis in L6 myotubes $(p<0.001)$. This dose was selected for our in vitro studies on the basis of a previous report [10]. Treatment of L6 myotubes with a lower concentration of LY-83583 (100 nmol/l) also increased glycogen synthesis (data not shown). Importantly, we provide evidence that only the $\alpha 1$ subunit of AMPK is present in L6 myotubes, since immunoblot analysis failed to detect the $\alpha 2$ subunit of AMPK (Fig. 4c).

\section{Discussion}

Regular exercise training improves glucose tolerance [27] and skeletal muscle insulin sensitivity [28] in type 2 diabetic patients, but the molecular mechanisms are incompletely resolved. Although several strategies designed to enhance compliance with physical activity regimens in patients with insulin resistance have been proposed [29], many type 2 diabetic patients rely on pharmacological treatments to improve glucose homeostasis. Yet, these current pharmacological treatments to enhance peripheral insulin sensitivity have limited efficacy [30]. Therefore, insight into novel mechanisms capable of enhancing skeletal muscle glucose uptake could lead to new pharmaceutical strategies to improve treatment and possibly prevent peripheral insulin resistance in patients with type 2 diabetes.

Nitric oxide signalling plays a key role in exercise/ contraction-induced metabolic responses in skeletal muscle [1], partly via an AMPK-dependent mechanism [15]. During exercise/contraction, increased nitric oxide levels are associated with induction of glucose uptake in skeletal muscle [2-4]. Conversely, NOS inhibition reduces glucose uptake during exercise in type 2 diabetic patients more than in control participants [31]. Previous reports characterising the direct effects of nitric oxide on glucose uptake are 


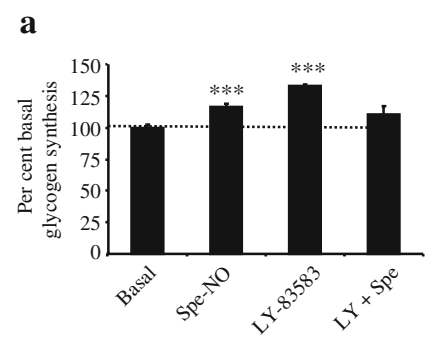

Fig. 4 Effect of the guanylate cyclase inhibitor LY-83583 on spermine NONOate induced-glycogen synthesis and AMPK phosphorylation. L6 myotubes were treated with spermine NONOate (Spe$\mathrm{NO}$, nitric oxide donor; $20 \mu \mathrm{mol} / \mathrm{l})$ and incubated in the absence or presence of LY-835883 (10 $\mu \mathrm{mol} / \mathrm{l})$. Glycogen synthesis $(n=5-8)(\mathbf{a})$

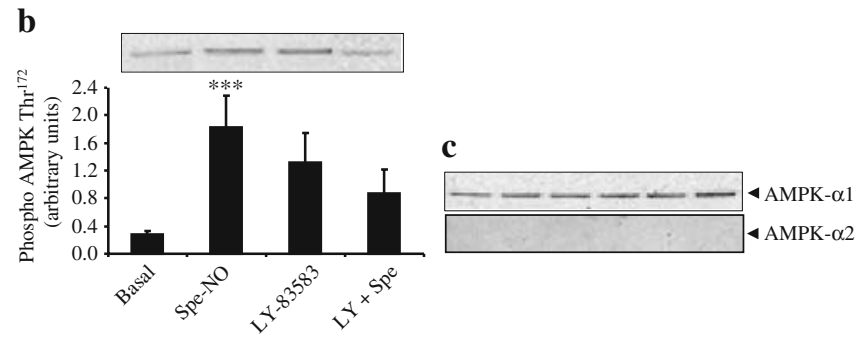

limited to in vitro studies of isolated rodent skeletal muscle [9-11]. Here we provide evidence that pharmacological treatment of human skeletal muscle with the nitric oxide donor spermine NONOate increases glucose transport, concomitant with increased cGMP levels and AMPK- $\alpha 1$ associated activity. Using L6 myotubes (producing only the $\alpha 1$-subunit of AMPK), we provide evidence that spermine NONOate increases phosphorylation of AMPK and ACC, with a concomitant increase in glucose transport and glycogen synthesis. Our findings in human skeletal muscle are compatible with earlier studies in rodent muscle indicating that nitric oxide donors increase cGMP levels and glucose transport [10]. Similar effects on glucose transport stimulation were also observed in isolated rat skeletal muscle exposed to the cGMP analogues 8-bromocGMP [10] and dibutyryl cGMP [11]. The mechanism by which cGMP regulates glucose uptake may involve two enzymes, namely guanylate cyclase and phosphodiesterase, but other mechanisms are also likely to be involved. Inhibition of guanylate cyclase prevents the sodium nitroprusside-induced increase in cGMP levels and glucose transport [10]. Conversely, treatment of isolated skeletal muscle with a phosphodiesterase inhibitor (Zaprinast) increases cGMP levels, with a concomitant increase in glucose uptake [32]. Collectively, these studies provide evidence that the nitric oxide/cGMP pathway is likely to be important in the regulation of glucose transport.

Nitric oxide signalling has been linked to AMPK activation and glucose uptake $[15,16]$. Here, we provide evidence that in vitro exposure to a nitric oxide donor increases glucose transport, with concomitant increase in AMPK- $\alpha 1$-specific activity and AMPK- $\alpha 1$ phosphorylation in isolated human skeletal muscle and L6 myotubes. Among the 12 possible AMPK heterotrimers, only three $(\alpha 1 \beta 2 \gamma 1, \alpha 2 \beta 2 \gamma 1, \alpha 2 \beta 2 \gamma 3)$ have been identified in human skeletal muscle [33]. Each individual heterotrimer is activated in a manner dependent on time and intensity $[34,35]$, which may elicit signalling specificity in response to a distinct set of stimuli. Our results in human skeletal and AMPK $\mathrm{Thr}^{172}$ phosphorylation $(n=5-6)$ (b) were determined. Results are reported as mean \pm SEM. Glucose incorporation into glycogen is expressed as percentage of basal. c Protein content of the AMPK- $\alpha 1$ and AMPK- $\alpha 2$ subunits was determined in L6 myotubes. $* * * p<0.001$ vs basal

muscle and L6 myotubes provide evidence that nitric oxide specifically increases AMPK- $\alpha 1$-associated activity and AMPK- $\alpha 1$ phosphorylation respectively. Moreover in L6 myotubes, the guanylate cyclase enzyme inhibitor LY83583 prevents the nitric oxide donor-induced increase in glycogen synthesis and $\alpha 1$-AMPK phosphorylation, providing evidence for a potential role of the AMPK- $\alpha 1$ subunit in the mechanism by which nitric oxide donors increase glucose transport. These observations are consistent with a previous study in rodent skeletal muscle [15], which provided evidence that sodium nitroprusside increases AMPK- $\alpha 1$-, but not AMPK- $\alpha 2$-associated activity. Furthermore, in rodent skeletal muscle, sodium nitroprusside-induced increases in AMPK-isoform-specific activity occurred independently of changes in ATP, creatinine phosphate or glycogen levels [15]. Thus, the nitric oxide-cGMP pathway may be involved in the regulation of AMPK- $\alpha 1$ activity and/or inhibition of the protein phosphatase responsible for AMPK regulation.

Although most Ampk (also known as Prkaa2) knockout models provide evidence against a critical role for the AMPK- $\alpha 1$ subunit in the regulation of skeletal muscle glucose uptake [14], AMPK- $\alpha 1$ activation is required for stimulation of glucose uptake in response to twitch contraction [36]. Based on our results, the promotion of glucose uptake effected by the nitric oxide donor appears to be at least partly mediated via AMPK complexes containing the $\alpha 1$ subunit. However, the role of AMPK in nitric oxide signalling is complex, since AMPK has also been suggested to be an upstream kinase for NOS [17-19, 37]. Direct activation of AMPK, using 5'-aminoimidazole-4carboxamide ribonucleoside (AICAR), stimulates nitric oxide production in human aortic endothelial cells [37] and increases NOS activity in $\mathrm{H}-2 \mathrm{~K}^{\mathrm{b}}$ cells [17], implicating a feedback loop between AMPK and NOS [16]. The question of whether nitric oxide pathways lie upstream or downstream of AMPK remains unresolved. For example, AICAR-induced AMPK-activated glucose transport is unaltered by NOS inhibition in isolated rat skeletal muscle 
[38]. The direct interaction between the nitric oxide/cGMP pathway and AMPK warrant further investigation.

To determine the intracellular mechanism by which the nitric oxide donor spermine NONOate increases glucose transport, components of the canonical insulin signalling cascade were assessed. The Akt- and Rev/Rex activation domain-binding protein (Rab) GTPase-activating proteins, TBC1D1 and TBC1D4, are the most distal signalling proteins implicated in GLUT4 translocation [39, 40]. In human skeletal muscle, insulin exposure led to an expected increase in phosphorylation of Akt, TBC1D1/D4 (detected using a PAS antibody) and GSK3, while exposure to the nitric oxide donor had no effect. These data indicate that nitric oxide-stimulated glucose transport is mediated via an insulin-independent pathway. Nitric oxide has also been linked as a positive [16] modulator of GLUT4 production. However, GLUT4 protein content was unaltered in response to spermine NONOate (data not shown), presumably because of the shorter incubation time and low concentration of the nitric oxide donor used in this study. CaMKII signalling has been implicated in the mechanism by which muscle contraction increases glucose uptake [13]. Nevertheless, CaMKII phosphorylation was unaltered in response to insulin or spermine NONOate. In contrast to our results for AMPK signalling, insulin and CaMKII signalling do not appear to play a role in nitric oxide action on skeletal muscle glucose transport. In L6 myotubes, the nitric oxide donor and insulin had an additive effect on glycogen synthesis and glucose uptake without further increase in insulin-induced Akt and TBC1D1/D4 phosphorylation. These results suggest that nitric oxide promotes glucose uptake by an insulin-independent mechanism. Furthermore, the stimulatory effect of the nitric oxide donor on AMPK and ACC phosphorylation under insulin-stimulated conditions was prevented, excluding a role for AMPK signalling in the additive effect on glycogen synthesis and glucose uptake.

In summary, the nitric oxide donor spermine NONOate increases cGMP levels and promotes glucose transport, concomitantly with AMPK- $\alpha 1$-isoform-specific activation in human skeletal muscle. Further study to delineate mechanisms and the therapeutic window is warranted. Spermine NONOate also increased glucose transport in L6 myotubes, concomitantly with an increase in AMPK$\alpha 1$-isoform-specific phosphorylation. Moreover, these effects were prevented in presence of a guanylate cyclase inhibitor. Further studies on the mechanisms by which AMPK- $\alpha 1$-isoform-specific signalling is directly linked to nitric oxide action are warranted. Taken together with recent evidence showing that sodium nitroprusside increased glucose uptake in human primary myotubes derived from healthy volunteers and patients with type 2 diabetes [41], our findings have clear clinical implications, since manipulation of the nitric oxide/cGMP signalling cascade could enhance glucose uptake by an insulin-independent mechanism to potentially improve whole-body glucose homeostasis in type 2 diabetic patients.

Acknowledgements This work was supported by grants from the European Research Council, the Swedish Research Council, the Swedish Diabetes Association, Novo Nordisk Foundation, the Foundation for Scientific Studies of Diabetology, the Swedish Centre for Sports Research, the Strategic Research Foundation, the Commission of the European Communities (Contract numbers LSHM-CT-2004-005272 EXGENESIS and LSHM-CT-2004-512013 EUGENE2). Additional support to H. A. Koistinen was provided by grants from Finnish Academy of Science and Sigrid Juselius Foundation.

Duality of interest The authors declare that there is no duality of interest associated with this manuscript.

Open Access This article is distributed under the terms of the Creative Commons Attribution Noncommercial License which permits any noncommercial use, distribution, and reproduction in any medium, provided the original author(s) and source are credited.

\section{References}

1. McConell GK, Kingwell BA (2006) Does nitric oxide regulate skeletal muscle glucose uptake during exercise? Exerc Sport Sci Rev 34:36-41

2. Balon TW, Nadler JL (1994) Nitric oxide release is present from incubated skeletal muscle preparations. J Appl Physiol 77:25192521

3. Roberts CK, Barnard RJ, Scheck SH, Balon TW (1997) Exercisestimulated glucose transport in skeletal muscle is nitric oxide dependent. Am J Physiol 273:E220-E225

4. Bradley SJ, Kingwell BA, McConell GK (1999) Nitric oxide synthase inhibition reduces leg glucose uptake but not blood flow during dynamic exercise in humans. Diabetes 48:1815-1821

5. Moncada S, Higgs A (1993) The L-arginine-nitric oxide pathway. N Engl J Med 329:2002-2012

6. Nakane M, Schmidt HH, Pollock JS, Förstermann U, Murad F (1993) Cloned human brain nitric oxide synthase is highly expressed in skeletal muscle. FEBS Lett 316:175-180

7. Durham WJ, Yeckel CW, Miller SL, Gore DC, Wolfe RR (2003) Exogenous nitric oxide increases basal leg glucose uptake in humans. Metabolism 52:662-665

8. Henstridge DC, Kingwell BA, Formosa MF et al (2005) Effects of the nitric oxide donor, sodium nitroprusside, on resting leg glucose uptake in patients with type 2 diabetes. Diabetologia 48:2602-2608

9. Balon TW, Nadler JL (1997) Evidence that nitric oxide increases glucose transport in skeletal muscle. J Appl Physiol 82:359-363

10. Young ME, Radda GK, Leighton B (1997) Nitric oxide stimulates glucose transport and metabolism in rat skeletal muscle in vitro. Biochem J 322:223-228

11. Etgen GJ Jr, Fryburg DA, Gibbs EM (1997) Nitric oxide stimulates skeletal muscle glucose transport through a calcium/ contraction- and phosphatidylinositol-3-kinase-independent pathway. Diabetes 46:1915-1919

12. Ohlstein EH, Wood KS, Ignarro LJ (1982) Purification and properties of heme-deficient hepatic soluble guanylate cyclase: effects of heme and other factors on enzyme activation by $\mathrm{NO}$, NO-heme, and protoporphyrin IX. Arch Biochem Biophys 218:187-198 
13. Jessen N, Goodyear LJ (2005) Contraction signaling to glucose transport in skeletal muscle. J Appl Physiol 99:330-337

14. Long YC, Zierath JR (2006) AMP-activated protein kinase signaling in metabolic regulation. J Clin Invest 116:1776-1783

15. Higaki Y, Hirshman MF, Fujii N et al (2001) Nitric oxide increases glucose uptake through a mechanism that is distinct from the insulin and contraction pathways in rat skeletal muscle. Diabetes 50:241-247

16. Lira VA, Soltow QA, Long JH et al (2007) Nitric oxide increases GLUT4 expression and regulates AMPK signaling in skeletal muscle. Am J Physiol Endocrinol Metab 293:E1062-E1068

17. Fryer LG, Hajduch E, Rencurel F et al (2000) Activation of glucose transport by AMP-activated protein kinase via stimulation of nitric oxide synthase. Diabetes 49:1978-1785

18. Chen ZP, Mitchelhill KI, Michell BJ et al (1999) AMP-activated protein kinase phosphorylation of endothelial NO synthase. FEBS Lett 443:285-289

19. Chen ZP, McConell GK, Michell BJ et al (2000) AMPK signaling in contracting human skeletal muscle: acetyl-CoA carboxylase and NO synthase phosphorylation. Am J Physiol Endocrinol Metab 279:E1202-E1206

20. Zierath JR (1995) In vitro studies of human skeletal muscle: hormonal and metabolic regulation of glucose transport. Acta Physiol Scand Suppl 626:1-96

21. Zierath JR, Galuska D, Engstrom A et al (1992) Human islet amyloid polypeptide at pharmacological levels inhibits insulin and phorbol ester-stimulated glucose transport in in vitro incubated human muscle strips. Diabetologia 35:26-31

22. Al-Khalili L, Chibalin AV, Kannisto K et al (2003) Insulin action in cultured human skeletal muscle cells during differentiation: assessment of cell surface GLUT4 and GLUT1 content. Cell Mol Life Sci 60:991-998

23. Niu W, Huang C, Nawaz Z et al (2003) Maturation of the regulation of GLUT4 activity by p38 MAPK during L6 cell myogenesis. J Biol Chem 278:17953-17962

24. Koistinen HA, Galuska D, Chibalin AV et al (2003) 5-aminoimidazole carboxamide riboside increases glucose transport and cell-surface GLUT4 content in skeletal muscle from subjects with type 2 diabetes. Diabetes 52:1066-1072

25. Barnes BR, Ryder JW, Steiler TL et al (2002) Isoform-specific regulation of $5^{\prime}$ AMP-activated protein kinase in skeletal muscle from obese Zucker (fa/fa) rats in response to contraction. Diabetes 51:2703-2708

26. Mulsch A, Busse R, Liebau S et al (1988) LY 83583 interferes with the release of endothelium-derived relaxing factor and inhibits soluble guanylate cyclase. J Pharmacol Exp Ther 247(1):283-288

27. Rogers MA, Yamamoto C, King DS et al (1988) Improvement in glucose tolerance after $1 \mathrm{wk}$ of exercise in patients with mild NIDDM. Diabetes Care 11:613-618
28. Kirwan JP, Solomon TPJ, Wojta DM, Staten MA, Holloszy JO (2009) Effects of 7 days of exercise training on insulin sensitivity and responsiveness in type 2 diabetes mellitus. Am J Physiol Endocrinol Metab 297:E151-E156

29. Kirk A, de Feo P (2007) Strategies to enhance compliance to physical activity for patients with insulin resistance. Appl Physiol Nutr Metab 32:549-556

30. Moller DE (2001) New drug targets for type 2 diabetes and the metabolic syndrome. Nature 414:821-827

31. Kingwell BA, Formosa M, Muhlmann M et al (2002) Nitric oxide synthase inhibition reduces glucose uptake during exercise in individuals with type 2 diabetes more than in control subjects. Diabetes 51:2572-2580

32. Young ME, Leighton B (1998) Evidence for altered sensitivity of the nitric oxide/cGMP signalling cascade in insulin-resistant skeletal muscle. Biochem J 329:73-79

33. Wojtaszewski JF, Birk JB, Frosig C et al (2005) 5'AMP activated protein kinase expression in human skeletal muscle: effects of strength training and type 2 diabetes. J Physiol 564:563-573

34. Wojtaszewski JF, Nielsen P, Hansen BF et al (2000) Isoformspecific and exercise intensity-dependent activation of 5'-AMPactivated protein kinase in human skeletal muscle. J Physiol 528:221-226

35. Treebak JT, Birk JB, Rose AJ et al (2007) AS160 phosphorylation is associated with activation of alpha2beta2gamma1- but not alpha2beta2gamma3-AMPK trimeric complex in skeletal muscle during exercise in humans. Am J Physiol Endocrinol Metab 292: E715-E722

36. Jensen TE, Schjerling P, Viollet B et al (2008) AMPK alpha1 activation is required for stimulation of glucose uptake by twitch contraction, but not by $\mathrm{H}_{2} \mathrm{O}_{2}$, in mouse skeletal muscle. PLoS ONE 3:e2102

37. Morrow VA, Foufelle F, Connell JM et al (2003) Direct activation of AMP-activated protein kinase stimulates nitric-oxide synthesis in human aortic endothelial cells. J Biol Chem 278:31629-31639

38. Stephens TJ, Canny BJ, Snow RJ et al (2004) 5'-Aminoimidazole4-carboxyamide-ribonucleoside-activated glucose transport is not prevented by nitric oxide synthase inhibition in rat isolated skeletal muscle. Clin Exp Pharmacol Physiol 31:419-423

39. Roach WG, Chavez JA, Miinea CP et al (2007) Substrate specificity and effect on GLUT4 translocation of the Rab GTPase-activating protein Tbc1d1. Biochem J 403:353-358

40. Sano H, Kane S, Sano E et al (2003) Insulin-stimulated phosphorylation of a Rab GTPase-activating protein regulates GLUT4 translocation. J Biol Chem 278:14599-14602

41. Henstridge DC, Drew BG, Formosa MF et al (2009) The effect of the nitric oxide donor sodium nitroprusside on glucose uptake in human primary skeletal muscle cells. Nitric Oxide 21:126-131 